\title{
Incorrect Protocol Artifact
}

National Cancer Institute

\section{Source}

National Cancer Institute. Incorrect Protocol Artifact. NCI Thesaurus. Code C87047.

An image of reduced quality resulting from the use of the wrong instructions. 